\title{
高速引張り試験における薄板試験片の向きと出カ棒の反りの黗霓*
}

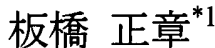

\section{Effect of the Angle between Sheet Specimen and Warp of Output Bar in High Velocity Tensile}

Test

\author{
Masaaki ITABASHI ${ }^{*}$ \\ ${ }^{* 1}$ Tokyo Univ. of Science, Suwa \\ 5000-1, Toyohira, Chino, Nagano 391-0292, Japan
}

So far, the one bar method gave satisfactory stress-strain curves for "cylindrical" specimens, at the strain rate of $1 \times 10^{3} \mathrm{~s}^{-1}$. On the other hand, for metallic "sheet" specimens only, the one bar method frequently detects an initial stress peak. The height of the peak is too high so that the extra height is apparent. One of the causes of this phenomenon is the deflection of the output bar end, as pointed out by Yoshida et al. in 2002. In order to get better alignment of the output bar, an output-bar supporting stand has been developed. Half-cut PTFE collars are installed in the stand. Via the collars, transverse compression to suppress the vibration can be applied to the output bar end. Comparing the quality of obtained dynamic tensile stress-strain curves, $50-190 \mathrm{~N}$ is the suitable compressive load range. Even though the supporting stand is introduced, a small number of dynamic stress-strain curves still have the extraordinary stress peak. The additional cause of the peak is supposed that there are troublesome angles between the sheet specimen and the warp of the output bar. After measuring the angle between each specimen and the warp, thirteen dynamic tensile tests are carried out with variations of the angle and compressive load to the output bar. Probably, the angle is not the additional cause of the extraordinary stress peak.

Key Words : High Velocity tensile Test, Sheet Specimen, Output Bar, Supporting Stand, Warp

\section{1. 辕}

ワンバー法 ${ }^{(1)}$ は自動車用鋼板の高速引張り試験方法として活用されてきているが，異常に高い上降伏応力を検 出してしまうことがある.このような現象は丸棒型の試験片では見られなかったが，板状の試験片形状と何かが 組み合わさって発生しているものと思われる.これまで著者はこの「何か」を発見しようと努力してきた．例え ば，試験片としての板の試験機への装着方法の変更 ${ }^{(2)}$, 吉田らによる指摘 (3) に従い出力棒端への支持具の追加 ${ }^{(4)}$, 出力棒との接触部分へのテフロン製カラーの導入(5), さらにそのカラーを二分割して適切な圧縮負荷の導入烏試 みてきた．残念ながら，異常に高い上降伏応力の検出を完全に排除できるようにはなっていない.この現象の頻 度を低减させる効果は着々と得られてはいるものの，根本的な解決に至らず歯がゆい思いをしてきた.

本研究では，長さ約 $3 \mathrm{~m}$ ，直径 $\phi 12 \mathrm{~mm}$ のステンレス鋼 SUS304 製の出力棒が最大 $10 \mathrm{~mm}$ 程度の反りを有してい ることに着目し，この反りが最大になる向きを基準として，この向きと試験片としての板との間の角度の影響を

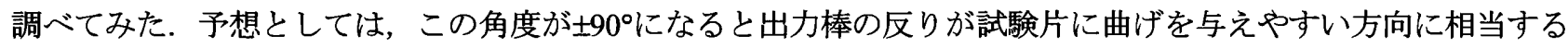
ので, 出力棒端に余計な横振動が発生して異常に高い上降伏応力を見かけ上発生させやすくなるものと考えた.

\section{2. 实 方 法}

\section{$2 \cdot 1$ ワンバー法にとっての出力㭺}

ワンバー法は引張り型のホプキンソン棒法 ${ }^{(7)}$ と実験結果に互換性はあるものの, 入力棒の代わりに衝撃ブロッ

\footnotetext{
${ }^{* 1}$ 正員, 骤訪東京理科大学 (テ391-0292 長野県茅野市豊平 5000-1)

E-mail: itabashi@rs.suwa.tus.ac.jp
} 
クを用いており，長い棒は出力棒のみである. したがって, ホプキンソン棒法よりは比較的長い出力棒を導入し やすく，測定可能時間を稼ぎやすい，一方，出力棒は細長いことを前提としているため，できるだけ真直度の良 い棒を素材として選ぶが長ければ長いほど若干の反りがあることは仕方がないものと考えてきた. 試験片装着部 付近のみがまっすぐであれば，引張り負荷と出力棒の弾性伸びを測定しているひずみゲージに悪影響を与えるこ とはなかろうという考え方である．試験片が丸棒の場合には，この考え方を許容する実験結果ばかりが得られて きており，やたらに高い初期応力ピークが観測されることはなかった．しかしながら，試験片が平板になると初 期応力ピークに悩まされることが多かった．吉田らの解析と実験により，ワンバー法では出力棒の先端がわずか 数十 $\mu \mathrm{m}$ たわんでいるだけで見かけ上の初期応力ピークが観測されてしまうことが示され, 出力棒のたわみを矯 正するために 2 本の円柱で出力棒をはさみ込むという手法でこの現象を文字通り抑え込んだ実験結果が報告され $た^{(3)}$. 著者はこの手法が水平方向の出力棒のたわみを矯正できるものの, 鉛直方向 (2 本の円柱の軸方向)につい ての効果が期待できないことに不安を感じていた.

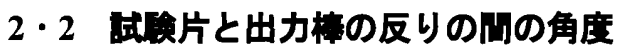

ワンバー法でもホプキンソン棒法でも試験片が板であることから, 図 1 に示すように出力棒側(左側) は出力棒 と同径の丸棒(attachment)に溝を切って, 試験片としての厚さ $1.0 \mathrm{~mm}$ の板を挿入して強力な接着剤(例えば, 電気 化学工業 ハードロック M372-20)を使って組み立てている. $\phi 3 \mathrm{~mm}$ の金属ピンを挿入しているのはあくまでも硬 化時の位置決めのためである. 丸棒の左側には M8 のめねじを切って, 出力棒先端のおねじに締め付けることに なる. めねじの切れ上がりと板を挿入するための溝の間の角度を一定にすることはできない. したがって, 組み 上がった試験片アセンブリを図 2 に示すように出力棒にねじ込んだ段階で, 試験片と出力棒の反りとの間の角度 (以後, 試験片角度と呼ぶ.) がこのとき初めて判明する. ちなみに, 図 1 の右側の部分はタブをスポット溶接で 付けた上で， $\phi 8 \mathrm{~mm}$ の穴を図 2 に示すように衝撃ブロック側の穴と合わせて回転自由の状態でピン結合する. 左 側の接着結合部のわずかな真直度のずれをここで解消させるようになっている.

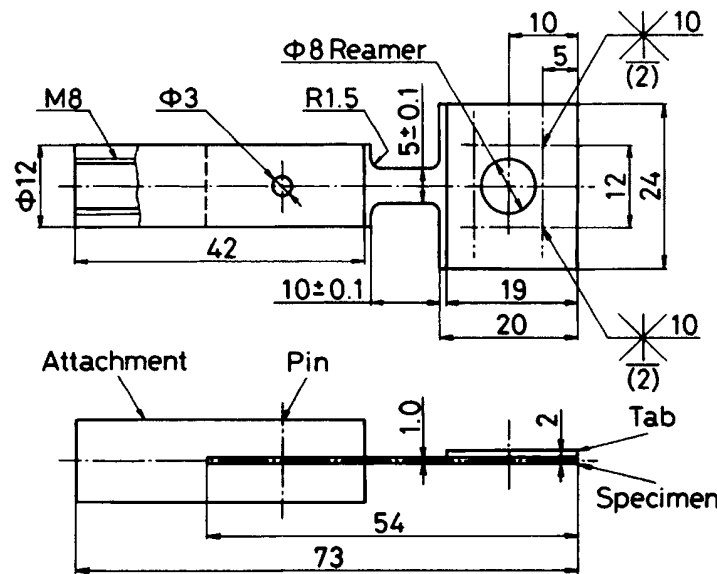

Fig.1 Specimen assembly for one-bar-method type testing machine
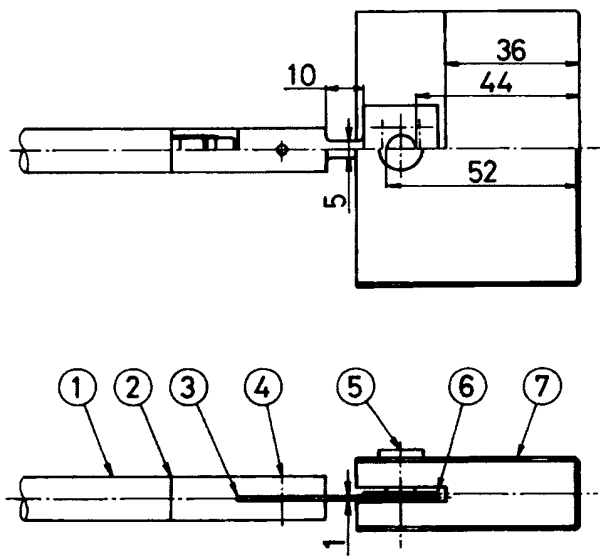

(1)Output bar (2)Attachment (3) Specimen (4) Positioning pin (5)Fastening pin (6) Tab (7)Impact block

Fig.2 Assembly drawing of tensile test setup for sheet steel

さて, 試験片角度は図 3 に示すように，理想的な出力棒の形状に対して最大限下方にたわんでいる部分を基準 として測定した. 出力棒に試験片アセンブリを一個一個ねじ結合してから, 図 3 の右側から見て図 4 のように時 計回りに試験片角度を計測していった. その計測結果を図 5 に示寸. やはり, 試験片角度はランダムに分布して いた.

\section{$2 \cdot 3$ 侙硂片}

薄板試験片としては, 自動車の車体構造用 440MPa 級ハイテン鋼を用いた. 化学成分は Fe-0.061C-0.03Si-0.60Mn- 


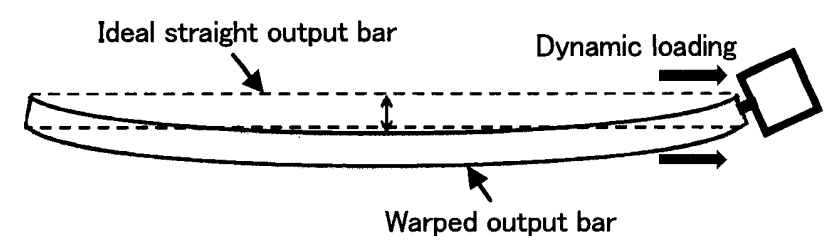

Fig.3 Warped output bar
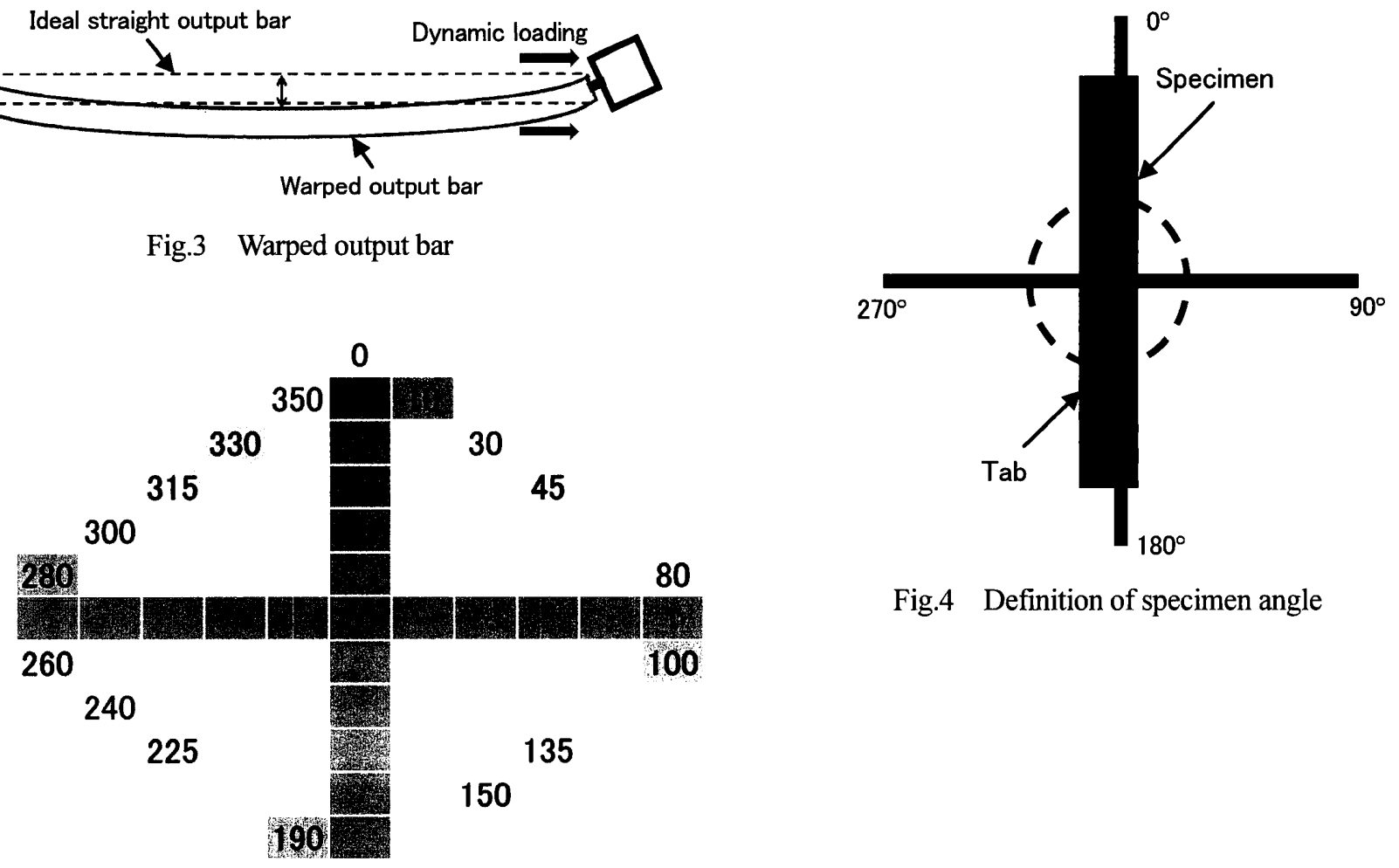

Fig.4 Definition of specimen angle

Fig.5 Variations in angle between sheet specimen and warp of the output bar

0.136P-0.012S-0.052Al-0.004N である. この鋼の動的負荷の下での上降伏応力は約 700MPa, 引張り強度は 600MPa である. 試験片の板厚は $1.0 \mathrm{~mm}$ であり，この試験片形状にとって最適な厚さである. ちなみに, 本研究で用いて いる実験装置では最大 $2.0 \mathrm{~mm}$ の板厚まで対応できる.

\section{$2 \cdot 4$ 实験条件}

図 5 のような試験片角度の分布を考慮しながら高速引張り試験を実施するのだが，文献(6)で得られた二分割式 のテフロン製カラーを介して出力棒に圧縮負荷を与える手法の効果の再確認も兼ねるため, 圧縮負荷 (本文および 図中では, 負荷を与えるためのねじの締付けトルクにて表示する. )を 3 段階に変化させた. それぞれの締付けト

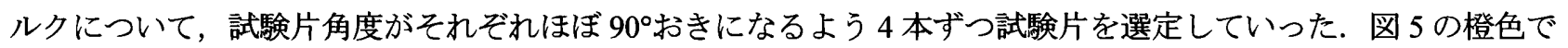
示した試験片角度は締付けトルクを $0 \mathrm{cN} \cdot \mathrm{m}$ ，青色で示した試験片角度は締付けトルクを $5 \mathrm{cN} \cdot \mathrm{m}$ ，緑色で示した試 験片角度は締付けトルクを $10 \mathrm{cN} \cdot \mathrm{m}$ とする高速引張り試験に供した.

高速引張り試験はワンバー法を採用した水平型ゴム動力式高速引張り実験装置 ${ }^{(8)}$ を用いた. 最大ひずみ速度と しては 552〜 715s $\mathrm{s}^{-1}$ での試験となった.

\section{3. 实睰結果および考宗}

高速引張り試験で得られた応力一ひずみ曲線を図 6〜8に示す.出力棒に全く圧縮負荷を与えていない図 6 の応 力一ひずみ曲線に注目していただきたい. 本来, 試験片番号 17 の実験で終了する予定だったが, 試験片角度 $330^{\circ}$ である試験片番号 16 の応力一ひずみ曲線に比較的高めの(見かけ上の) 上降伏応力が観測された. そこで, これに 近い試験片角度 $350^{\circ}$ である試験片番号 18 の実験を追加した. 出力棒に全く圧縮負荷を与えなければ高い初期応 カピークは出やすくなるが，試験片番号 18 の実験結果は，他の試験片番号 14, 15, 17 とほぼ同一の実験結果を示 していて試験片番号 16 の実験結果を再現できなかった. ましてや, 当初試験片角度が \pm 90 の応力一ひずみ曲線に 高い初期応力ピークが出やすいと予想していたものの, それに近い実験条件は試験片番号 8(試験片角度 $280^{\circ}$ ), 


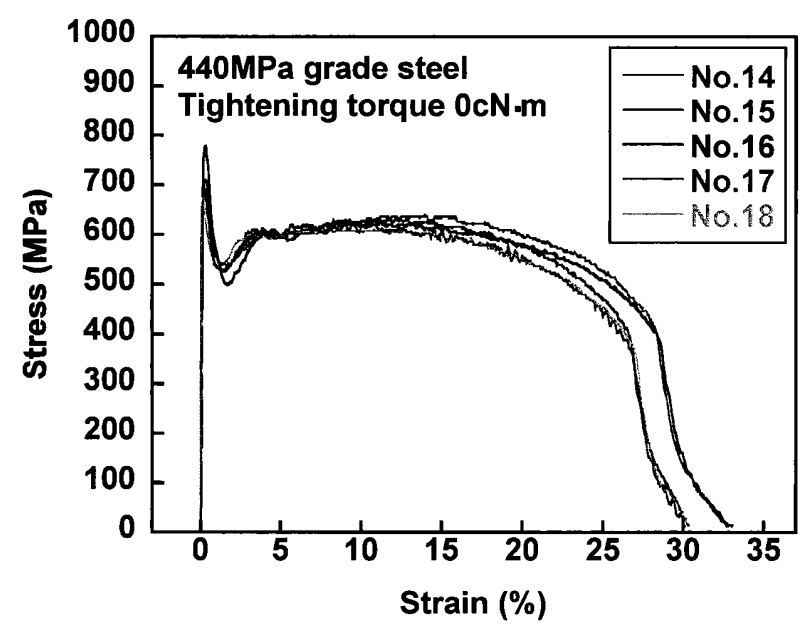

Fig.6 Dynamic tensile stress-strain curves for $440 \mathrm{MPa}$ grade steel with tightening torque of $0 \mathrm{cN} \cdot \mathrm{m}$

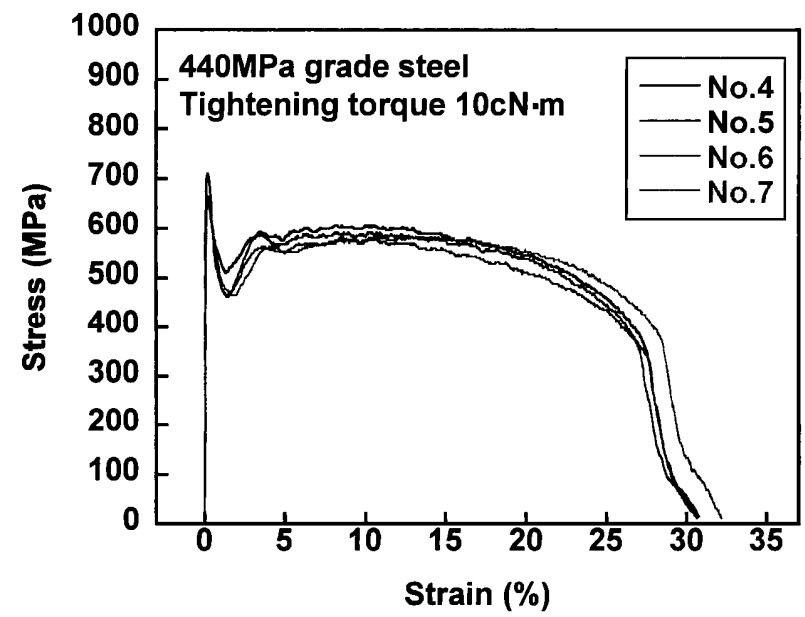

Fig.8 Dynamic tensile stress-strain curves for $440 \mathrm{MPa}$ grade steel with tightening torque of $10 \mathrm{cN} \cdot \mathrm{m}$

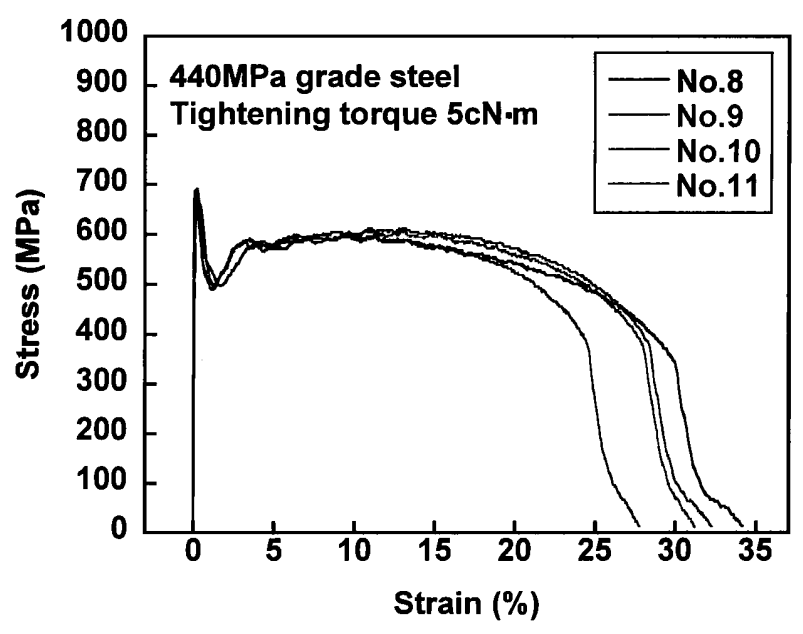

Fig.7 Dynamic tensile stress-strain curves for $440 \mathrm{MPa}$ grade steel with tightening torque of $5 \mathrm{cN} \cdot \mathrm{m}$

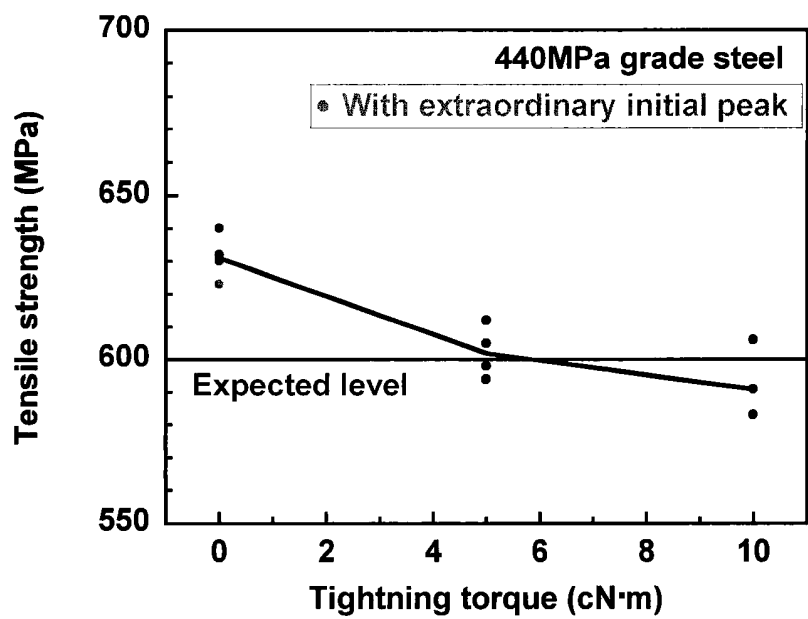

Fig.9 Comparison of tensile strengths with varying tightening torque

11 $\left(100^{\circ}\right), 14\left(260^{\circ}\right), 17\left(80^{\circ}\right)$ であったにも関わらず，いずれの曲線も高い初期応力ピークは出ておらず予想に全く反 した実験結果となった。

図 9 は得られた実験結果の中から引張り強度の值のみを取り上げて，期待されていた $600 \mathrm{MPa}$ 程度に収まって いるかどうかを確認したものである. 締付けトルク 0cN.m のデータの赤いプロットは高い初期応力ピークを伴う 実験結果であるが，他の同条件のものと大きく離れた引張り強度にはなっていない. なお，適切な締付けトルク を文献(6)では $10 \mathrm{cN} \cdot \mathrm{m}$ と結論付けたが，今回の一連の実験の中では $5 \mathrm{cN} \cdot \mathrm{m}$ も十分許容できる実験結果を与えてい るといえよう。

\section{4. 結}

ワンバー法の出力棒については, 引張り型のホプキンソン棒法よりも長めの出力棒を用いることが容易ではあ るが，その分棒の反りについてどこまで許容できるかについては明らかにされていなかった．今回はその反りが 高速引張り試験の実験結果に影響を与えるのではないかと思い，事前に試験片アセンブリを実験装置に装着した ときの試験片としての板と反りが最大になっているところの間の角度を測定しておき，一連の高速引張り試験を 実施した. 出力棒の先端に横振動を抑制させるための圧縮負荷を与えていない場合のみ，異常に高い上降伏応力 を一度だけ観測したが，同様な試験片を用いてもその現象を再現することができなかった．ただし，同様な角度 
の試験片がもっと多数手元にあれば再現できた可能性は否定できない. 本研究では，いちおう出力棒の反りと試 験片の角度の間には関係性が見い出せなかったとしておく，一方，出力棒への圧縮荷重が 50〜190N だと良い実 験結果が得やすいことを再確認することができた.

\section{辞}

卒業論文のテーマとして，本研究に鋭意取り組んでくれた本学機械システム工学科の田村昌弘君に謝意を表す る.

\section{文南}

(1) Kawata, K., Hashimoto, S., Kurokawa, K. and Kanayama, N., "A New Testing Method for the Characterization of Materials in High Velocity Tension," Mechanical Properties at High Rates of Strain 1979, Harding, J. Editor, Institute of Physics (1979), pp.71-80.

(2) Itabashi, M., "High Velocity Tensile Test for Thin Plate Specimen with One Bar Method," JSME International Journal, Series $A$, Vol.46, No.3 (2003), pp.316-321.

（3）吉田博司，栗山幸久，上西朗弘，高橋学，"one bar 法による鋼材の高速変形特性の高精度評価," 2002 年度春季大会 前刷集，自動車技術会，20025235 (2002).

(4) Itabashi, M., "Effect of Output Bar Supporting Methods on High Velocity Tensile Behavior for Steel Plate," Journal of Solid Mechanics and Materials Engineering, Vol.3, No.2 (2009), pp.295-307.

(5) Itabashi, M., "Improvement of Output Bar Support with a Polytetrafluoroethylene Collar on High Velocity Tensile Test for Steel Plate," Journal of Solid Mechanics and Materials Engineering, Vol.5, No.12 (2011), pp.765-773.

(6) Itabashi, M., "Development of an Output-Bar Supporting Stand to Suppress Transverse Vibration in Dynamic Tensile Test of Sheet Steel," Abstracts Book, The 8-th International Symposium on Impact Engineering (ISIE2013) (2013), p.115.

(7) Kolsky, H., "An Investigation of the Mechanical Properties of Materials at Very High Rates of Loading," Proceedings of the Physical Society, Section B, Vol.62, No.11 (1949), pp.676-700.

(8) Itabashi, M. and Kawata, K., "Carbon Content Effect on High-Strain-Rate Tensile Properties for Carbon Steels," International Journal of Impact Engineering, Vol.24, No.2 (2000), 117-131. 